ARTICLE OPEN

\title{
The rumen microbiome: an underexplored resource for novel antimicrobial discovery
}

Linda B. Oyama', Susan E. Girdwood ${ }^{1}$, Alan R. Cookson ${ }^{1}$, Narcis Fernandez-Fuentes ${ }^{1}{ }^{1}$, Florence Privé ${ }^{1}$, Hannah E. Vallin ${ }^{1}$, Toby J. Wilkinson ${ }^{1}$, Peter N. Golyshin $\mathbb{D}^{2}{ }^{2}$, Olga V. Golyshina ${ }^{2}$, Ralf Mikut ${ }^{3}{ }^{3}$, Kai Hilpert ${ }^{4}$, Jennifer Richards ${ }^{5}$, Mandy Wootton ${ }^{5}$, Joan E. Edwards ${ }^{6}$, Marc Maresca ${ }^{7}$, Josette Perrier ${ }^{7}$, Fionnuala T. Lundy ${ }^{8}$, Yu Luo ${ }^{8}$, Mei Zhou ${ }^{9}$, Matthias Hess ${ }^{10}$, Hilario C. Mantovani ${ }^{11}$, Christopher J. Creevey ${ }^{1}$ and Sharon A. Huws ${ }^{12}$

Antimicrobial peptides (AMPs) are promising drug candidates to target multi-drug resistant bacteria. The rumen microbiome presents an underexplored resource for the discovery of novel microbial enzymes and metabolites, including AMPs. Using functional screening and computational approaches, we identified 181 potentially novel AMPs from a rumen bacterial metagenome. Here, we show that three of the selected AMPs (Lynronne-1, Lynronne-2 and Lynronne-3) were effective against numerous bacterial pathogens, including methicillin-resistant Staphylococcus aureus (MRSA). No decrease in MRSA susceptibility was observed after 25 days of sub-lethal exposure to these AMPs. The AMPs bound preferentially to bacterial membrane lipids and induced membrane permeability leading to cytoplasmic leakage. Topical administration of Lynronne- 1 (10\% w/v) to a mouse model of MRSA wound infection elicited a significant reduction in bacterial counts, which was comparable to treatment with $2 \%$ mupirocin ointment. Our findings indicate that the rumen microbiome may provide viable alternative antimicrobials for future therapeutic application.

npj Biofilms and Microbiomes (2017)3:33; doi:10.1038/s41522-017-0042-1

\section{INTRODUCTION}

The global increase of multi-drug resistant (MDR) bacteria, combined with the decreasing number of novel and effective antibacterial agents being developed for the market, poses a serious global threat to human health. ${ }^{1,2}$ Urgency is required with respect to discovery and development of novel antibiotics, alongside antimicrobial stewardship and development of rapid tools to detect MDR bacteria. ${ }^{3}$ Antimicrobial peptides (AMPs), particularly cationic AMPs, are promising alternatives to currently available antibiotics, due to their broad spectrum activity against Gram positive and Gram negative bacteria, and their rapid mode of action on the cytoplasmic membrane, which results in a decreased rate of resistance being developed by the targeted pathogens. However, synthetic generation of AMPs has produced very few if any viable AMPs for medical use, thus there is a need to further prospect from nature. ${ }^{4}$

Depending on availability of resources, bacteria in communities can either be symbiotic with one another or live in competition. ${ }^{5}$ In order to compete, bacteria often up-regulate genes encoding AMPs to kill other bacteria in the community. ${ }^{5}$ The rumen is an example of such a highly competitive community with a very complex microbiome, composed of unique and diverse range of bacteria, archaea, protozoa, fungi, and viruses ${ }^{6,7}$ and as such is a potentially unique resource for novel AMP discovery. ${ }^{8-10}$ In the past few years, it has become apparent that culture dependent methods to evaluate microbial populations substantially underestimates the diversity of microorganisms present, and only around $10-20 \%$ of the species from the rumen environment have been cultured to date. ${ }^{11,12}$ The limitations surrounding culturability and antimicrobial discovery can be circumvented using sequence and functional-based metagenomics, which allow mining of whole microbiomes for novel bioactive compounds. ${ }^{13,14}$

Here, we report the discovery and characterization of three AMPs (i.e., Lynronne-1, Lynronne-2 and Lynronne-3) via functional metagenomic screening of a rumen bacterial metagenomic library and in-silico sequence data analysis. These novel AMPs from the rumen microbiome have the potential to treat MDR bacterial infections.

\section{RESULTS}

Identification of AMPs

A metagenomic library consisting of 8448 fosmids from the plantattached rumen microbiome ${ }^{15}$ was screened for antimicrobial activity by a combination of agar-based functional screening, sequencing of positive clones and bioinformatic prediction of AMP sequences. To

\footnotetext{
${ }^{1}$ Institute of Biological Environmental and Rural Sciences, Aberystwyth University, Aberystwyth, Wales SY23 3DA, UK; ${ }^{2}$ Bangor University, Bangor, Gwynedd LL57 2DG, UK; ${ }^{3}$ Karlsruhe Institute of Technology, Hermann-von-Helmholtz-Platz 1, 76344 Eggenstein, Leopoldshafen, Germany; ${ }^{4}$ Institute of Infection and Immunity, St. George's University of London, Cranmer Terrace, London SW17 ORE, UK; ${ }^{5}$ Specialist Antimicrobial Chemotherapy Unit, Public Health Wales, University Hospital of Wales, Heath Park, Cardiff CF14 4XW, UK; ${ }^{6}$ Wageningen University \& Research, 6708 WE, Wageningen, Netherlands; ${ }^{7}$ Aix Marseille Université, CNRS, Central Marseille, iSm2, Marseille, France; ${ }^{8}$ Centre for Experimental Medicine, School of Medicine, Dentistry and Biomedical Sciences, Queen's University Belfast, Belfast, Northern Ireland BT9 7BL, UK; ${ }^{9}$ School of Pharmacy, Queens's University Belfast, Belfast, BT9 7BL, Northern Ireland, UK; ${ }^{10}$ UC Davis, College of Agricultural and Environmental Sciences, California 95616, USA; ${ }^{11}$ Department of Microbiology, Universidade

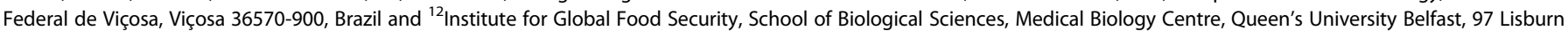
Road, Belfast, Northern Ireland BT9 7BL, UK

Correspondence: Sharon A. Huws (S.Huws@qub.ac.uk)
}

Received: 1 August 2017 Revised: 4 October 2017 Accepted: 6 November 2017

Published online: 01 December 2017 
test the antimicrobial activity of fosmid clones, lawns of pathogens including methicillin-sensitive Staphylococcus aureus (MSSA) RN4220, Escherichia coli K12, Salmonella enterica serovar Typhimurium SL1344, Listeria monocytogenes NCTC 11994 (serovar 4b) and Enterococcus faecalis $\mathrm{JH} 2-2$ were inoculated on appropriate agar medium and the clones were gently transferred on top using multichannel pin replicators. After an incubation period of $24 \mathrm{~h}$ at the appropriate temperatures, 255 fosmids produced clearing zones in the pathogen lawn, indicating that the metagenome clones carried inserts with antimicrobial activity. Of these clones, twenty-four were selected randomly and sequenced using the GS FLX system. A summary of the assembly metrics of the twenty-four metagenomic inserts with antimicrobial activity is provided in Supplementary Table S1. The full fosmid sequences are available in the GenBank database under the BioProject PRJNA264884; BioSample IDs: SAMN063330279 to SAMN063330302. Prediction of AMPs from the identified open reading frames (ORFs) yielded a total of 181 AMPs. A peptide library consisting of 135 of these AMPs ( $\leq 25$ amino acids (AAs)) was synthesized and screened for antimicrobial activity using the SPOT technique (synthesis of large numbers of peptides on marked spots on cellulose membrane sheets allowing for subsequent highthroughput screening). ${ }^{16}$ Twenty-five active AMPs were identified in this screen (Supplementary Table S2). Candidates, Lynronne-1 (19 AAs: LPRRNRWSKIWKKVVTVFS-NH ${ }_{2}$ ), Lynronne-2 (20 AAs: HLRRINKLLTRIGLYRHAFG-NH ${ }_{2}$ ) and Lynronne-3 (20 AAs: NRFTARFRRTPWR LCLQFRQ- $\mathrm{NH}_{2}$ ) encoded in fosmid clones SABPL29H11, SABPL5A1 and SABPL12(2)A3, respectively and were selected for further analysis due to their broad spectrum antibacterial activity and lower minimum inhibitory concentration (MIC) values. The nucleotide and protein sequences of the ORFs from which they were derived are available in the GenBank database under accession numbers KY628802, KY628803 and KY628804, respectively. Sequences upstream and downstream of these ORFs are shown in Supplementary Fig. S1. The likely producers of Lynronne-1, Lynronne- 2 and Lynronne-3 were identified as Prevotella ruminicola 23 (CP002006.1), Uncultured bacterium Contig939 (KC246977.1) and Uncultured bacterium Contigcl_1559 genomic sequence (KC246861.1) respectively (Supplementary Table S3 and Supplementary Fig. S2). Structural modelling using PEP-FOLD ${ }^{17}$ indicate that these peptides adopt a a-helical conformation of amphipathic nature, an arrangement typical of many a-helical AMPs $^{18}$ (Fig. 1). The AMPs have a net positive charge of $+6,+5$ and +6 , respectively with a hydrophobicity ratio of $\geq 40 \%$.

Antimicrobial activity, resistance and mechanism of action

The antibacterial activity of Lynronne-1, Lynronne-2 and Lynronne-3 against twenty-nine clinically important multidrugresistant pathogens was explored. All three peptides had promising activity against Gram-positive pathogens, including MDR strains (Table 1). Lynronne- 1 had an MIC range of $8-32$, Lynronne-2: $32-256$ and Lynronne-3: $32-128$ of $\mu \mathrm{g} / \mathrm{ml}$ for methicillin-resistant $S$. aureus (MRSA) strains. Since cationic peptides rarely demonstrate high in vitro antimicrobial activities seen with some conventional antibiotics, the MICs determined for Lynronne-1, Lynronne-2 and Lynronne-3 were not surprising and fall within the range of many commercially available AMPs. ${ }^{19,20}$

Lynronne-1, Lynronne-2 and Lynronne-3 (at $3 \times$ MIC) had relatively faster bactericidal activity against three MRSA strains when compared to vancomycin, a first line drug for MRSA (Fig. 2a, and Supplementary Fig. S3a, b). Reductions of $>8 \log _{10} \mathrm{CFU} / \mathrm{ml}$ occurred within the first $10 \mathrm{~min}$ for Lynronne- 1 and Lynronne-3, and $>3 \log _{10} \mathrm{CFU} / \mathrm{ml}$ in $30 \mathrm{~min}$ for Lynronne-2 (Fig. 2a, and Supplementary Fig. S3a, b). Vancomycin at $3 \times$ MIC produced between 1 to $>4 \log _{10}$ CFU/ml reductions depending on the MRSA strain. This can be attributed to difference in kill kinetics and mode of action. ${ }^{21}$ Time dependent killing of E. coli $\mathrm{K} 12$ was investigated to ascertain the efficacy of the peptides against Gram-negative bacterial strains. All three AMPs caused a rapid decrease in E. coli
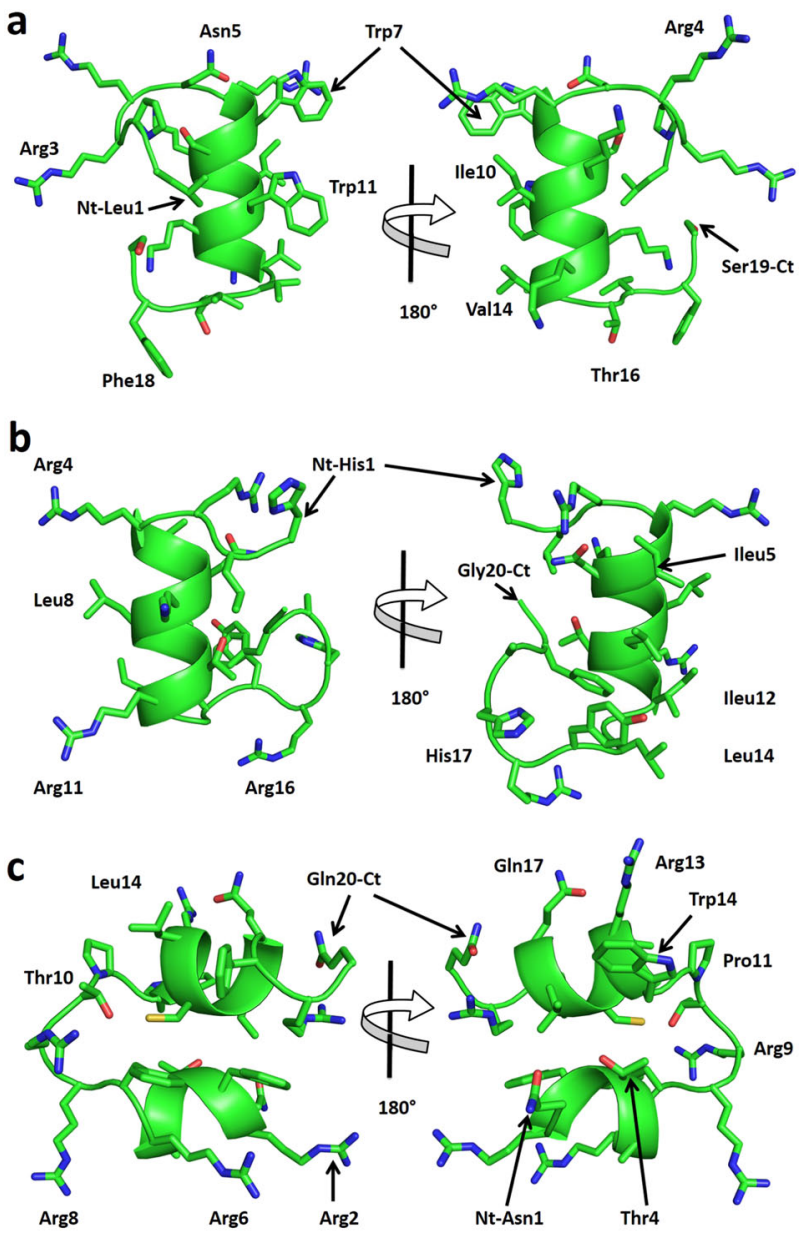

Fig. 1 Predicted structures for peptides: Lynronne-1, Lynronne-2 and Lynronne-3. a Lynronne-1, b Lynronne-2 and c Lynronne-3. Main-chain and side chains depicted in ribbon and stick representation respectively and colored according to atom type: carbon, oxygen and nitrogen in green, red and blue respective. Two orientations are shown rotated about the shown axis. $\mathrm{Ct}$ and $\mathrm{Nt}(\mathrm{C}$ and $\mathrm{N}$ terminals) as well as selected residues are depicted in the figure. Figures were rendered using PyMol

$\mathrm{K} 12$ viability at $3 \times$ MIC with complete cell death occurring within 10 min (see Supplementary Fig. S4a). Control agents, Polymyxin B and ciprofloxacin showed expected bactericidal activities ${ }^{22}$ (>4 $\log _{10} \mathrm{CFU} / \mathrm{ml}$ ) against $E$. coli $\mathrm{K} 12$ at $10 \mathrm{~min}$ and $3 \mathrm{~h}$, respectively (see Supplementary Fig. S4a).

Serial passage of MRSA strains in the presence of sub-MIC levels of Lynronne-1, Lynronne-2 and Lynronne-3 over a period of 25 days failed to produce mutants that were resistant to the AMPs (Fig. 2b and Supplementary Fig. S3c, d), suggesting a non-specific mode of action. ${ }^{23}$ The efficacy of Lynronne-1, Lynronne- 2 and Lynronne-3 against $S$. aureus biofilm attachment and established biofilms at sub and supra-MIC concentrations were tested. MRSA ATCC 33591 strain was used in this assay as it was a better biofilm former in our hands than the other strains (results not shown). All AMPs decreased biofilm attachment at $2 \times$ MIC concentrations (Fig. 2c) and Lynronne-2 was effective even at $0.25 \times$ MIC (data not shown). Anti-biofilm activity against established biofilms was observed with all peptides at $\geq 2 \times$ MIC concentrations (Fig. $2 \mathrm{C}$ ).

Importantly, Lynronne-1, Lynronne-2 and Lynronne-3 also showed little haemolytic activity against red blood cells (Fig. 2 d). Similarly, Lynronne-1, Lynronne-2 and Lynronne-3 were less cytotoxic to mammalian HUVEC and HepG2 cells when compared 


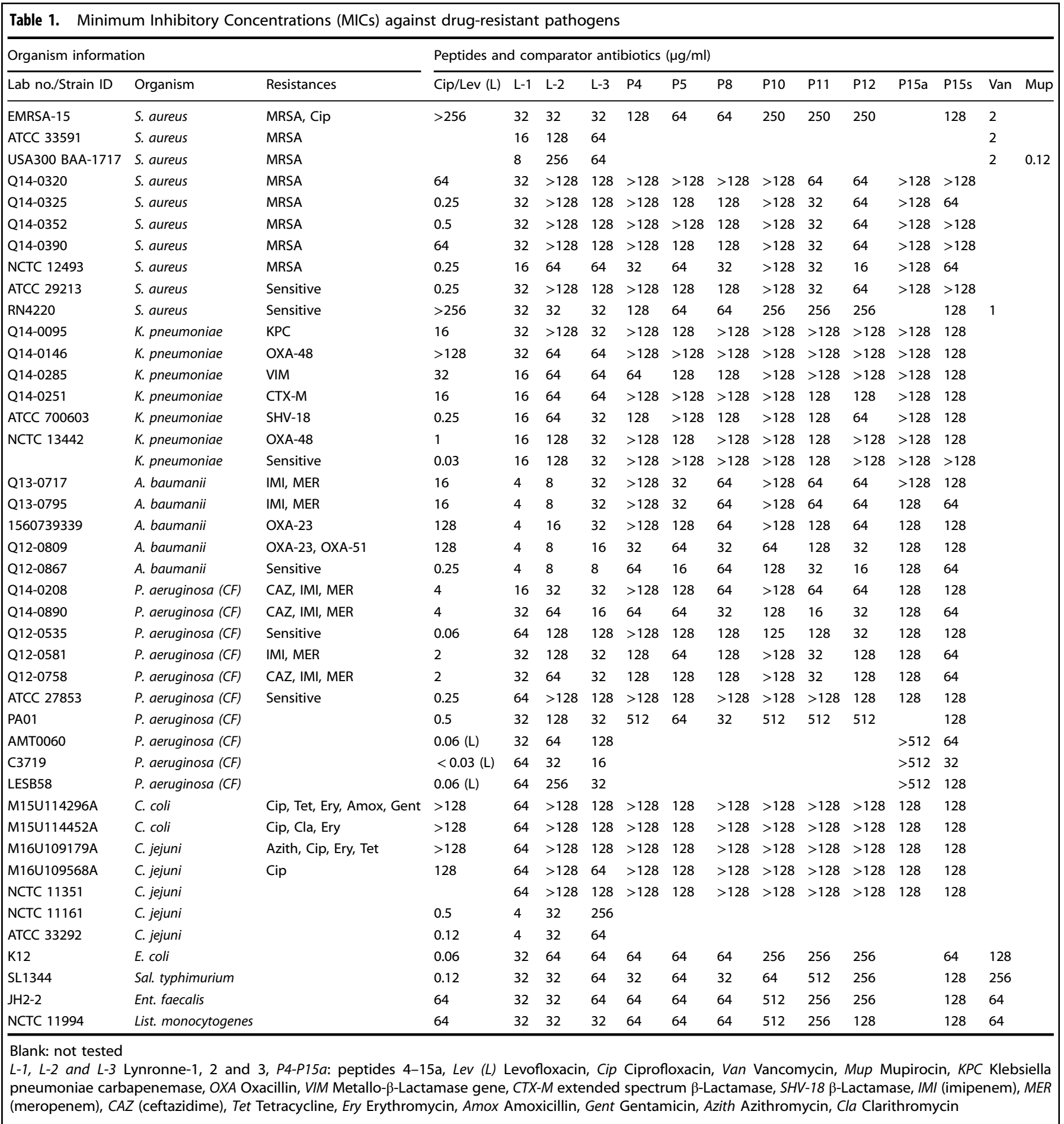

to the positive control agent, Staurosporine, which had 50\% growth inhibition $\left(\mathrm{Gl}_{50}\right)$, total growth inhibition (TGl) and $50 \%$ lethal concentration $\left(\mathrm{LC}_{50}\right)$ of $0.00047,0.0047$ and $0.014 \mu \mathrm{g} / \mathrm{ml}$ respectively. Lynronne- 2 had no cytotoxic activity against mammalian HUVEC and HepG2 cells at the highest concentration tested $(128 \mu \mathrm{g} / \mathrm{ml})$ while Lynronne-3 had little cytotoxicity at concentration close to the MIC with $\mathrm{GI}_{50}, \mathrm{TGI}$ and $\mathrm{LC}_{50}$ of $24.4,61.2$ and $>128 \mu \mathrm{g} / \mathrm{ml}$ respectively. Lynronne- 1 on the other hand, had low toxicity at concentrations above the MIC with $\mathrm{Gl}_{50}, \mathrm{TGI}$ and $\mathrm{LC}_{50}$ of $45.9,67.1$ and $98.1 \mu \mathrm{g} / \mathrm{ml}$ respectively. Whereas Lynronne1 and 3 were able to permeabilize MRSA USA300 cell membrane, very little permeabilization activity was observed for Lynronne-2 even at $>3$ times its MIC concentration (Fig. $3 a$ and Supplementary Fig. S5a), demonstrating that although antimicrobial activity of Lynronne- 1 and 3 is due to pore formation, mechanism of action of Lynronne- 2 may be different. In accordance with cytotoxicity results, Lynronne-1, Lynronne-2 and Lynronne-3 were less able to permeabilize eukaryotic membranes (Hep2G) compared to bacterial cell membranes (Supplementary Fig. S5b).

Since bacterial membrane permeabilization was demonstrated by the newly identified AMPs, we used lipid monolayer (Langmuir balance) to narrow down the potential lipids that are targeted by 


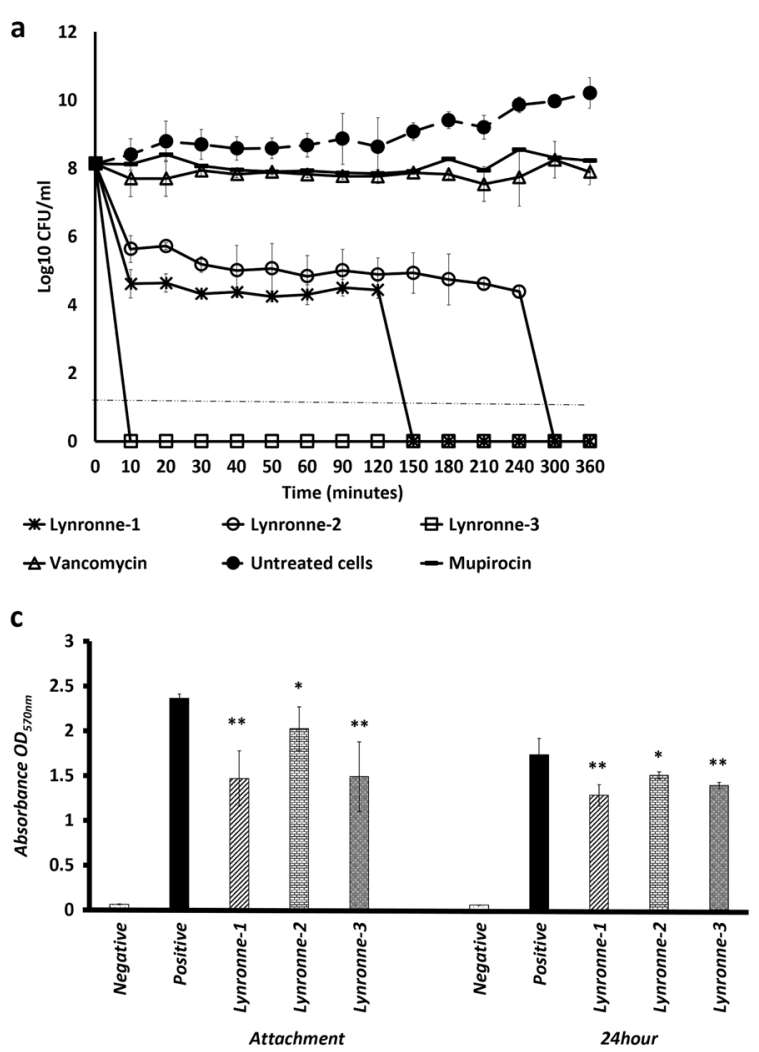

Peptide treatment at 2XMIC concentration

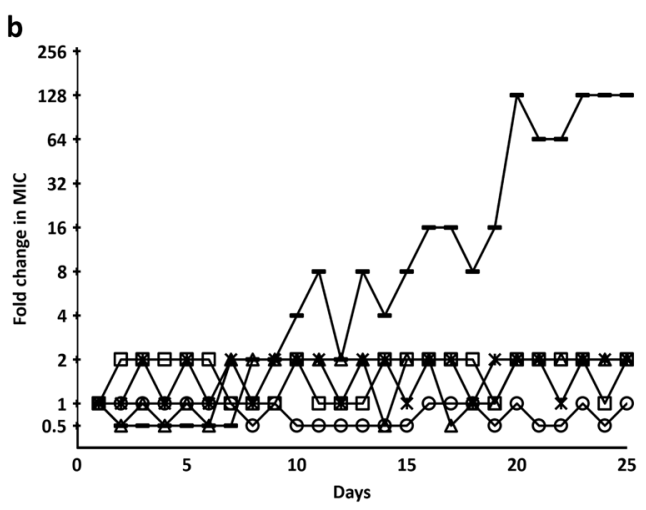

*Lynronne-1 $\ominus$ Lynronne-2 $\boxminus$ Lynronne-3 $A$ Vancomycin -Mupirocin

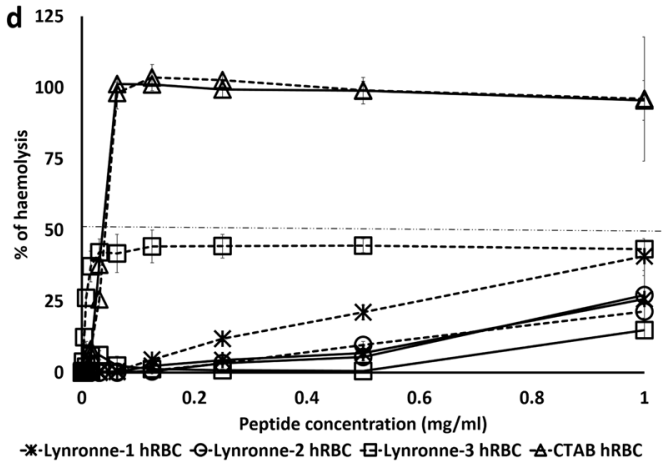

*-Lynronne-1 SRBC $\theta$ Lynronne-2 sRBC —Lynronne-3 sRBC $\triangle$ ACTAB SRBC

Fig. 2 Antimicrobial activity and haemolytic activity of Lynronne-1, Lynronne-2 and Lynronne-3. a Time-dependent kill of MRSA USA300 by antimicrobial compounds at $3 \times$ MIC concentration. Dashed lines indicate limit of detection. $\mathbf{b}$ Resistance acquisition during serial passaging of MRSA USA300 cells in the presence of sub-MIC levels of antimicrobials. The $y$ axis is the fold change in MIC during passaging. For mupirocin, $256 \times$ MIC was the highest concentration tested. The figure is representative of three independent experiments. c Quantification of anti-biofilm activity (MRSA 33591): ${ }^{*}$ and ${ }^{* *} P<0.05$ and 0.01 respectively-significantly different from untreated cells (positive). d Haemolytic activity, dashed line indicates $50 \%$ haemolysis. Values from at least three independent replicates; error bars represent the standard deviation)

these peptides. The use of MRSA lipid extract demonstrated a higher insertion ability of Lynronne-1 and Lynronne-3 compared to Lynronne-2 (Fig. 3b) and is in agreement with bacteria membrane permeabilization. The use of pure lipids demonstrated that Lynronne-1, Lynronne-2 and Lynronne-3 preferentially interact with lipids specific to bacteria, including 1-palmitoyl-2-oleoylsn-glycero-3-(phospho-rac-(1-glycerol)) (POPG), cardiolipin, lipoteichoic acid (LTA) or phosphatidylethanolamine (POPE) (also present in the inner membrane leaflet of eukaryotes) above lipids only present in eukaryotes, such as palmitoyloleoylphosphatidylcholine (POPC) (Fig. 3c and Supplementary Fig. S5c, d). This may explain the limited haemolytic and cytotoxic activity against mammalian cells in spite of their antibacterial activity. Interestingly, Lynronne-2 showed the highest affinity for LTA demonstrated by measurement of the critical pressure of insertion of the peptides in the different lipids (Supplementary Fig. S5d), suggesting that this peptide could target other molecules containing teichoic acid moieties, including cell wall teichoic acids and may also explain its antimicrobial activity in the absence of poreformation in whole bacteria. Transmission electron micrographs of cells treated with Lynronne-1, Lynronne-2 and Lynronne-3 (at $3 \times$ MICs for $1 \mathrm{~h}$ ) reveal varying changes in cell morphology and some cytoplasmic leakage (Fig. 4 and Supplementary Fig. S4b). MRSA USA300 cells treated with Lynronne-2 showed very little morphology changes, corresponding to the low permeabilization activity of the peptide. Further investigation into events leading up to changes in cell morphology may be required as the transmission electron microscopic analysis is semi-quantitative.
In vivo efficacy

Given the promising in vitro activity of Lynronne-1, Lynronne-2 and Lynronne-3, we investigated their in vivo therapeutic potential within a murine model of MRSA skin infection. ${ }^{24}$ Topical administrations of Lynronne-1 $(2 \% \mathrm{w} / \mathrm{v})$, in a group of mice with MRSA infected wounds (five mice/group) once daily for 3 days was associated with a significant decrease $(P<0.01)$ in the colony count relative to the control group treated with phosphatebuffered saline (PBS, pH 7.4) (Fig. 5a). However, this decrease was less than a 2 -log reduction $(\geq 99 \%)$ in colony counts. No significant decreases in colony counts were observed in the animal groups treated with Lynronne-2 $(2 \% \mathrm{w} / \mathrm{v})$ and Lynronne-3 $(2 \% \mathrm{w} / \mathrm{v})$. The reference, $2 \%$ mupirocin ointment (Dermasafe $e^{\circ}$ Ointment) was associated with a significant reduction ( $>2$-log reduction, and $P<$ 0.001 ) in bacterial counts, consistent with historical data. ${ }^{24}$ Given this promising in vivo result for Lynronne-1, we further tested its efficacy at a higher dose $(10 \% \mathrm{w} / \mathrm{v})$ in the wound model. Lynronne- 1 at $10 \%(\mathrm{w} / \mathrm{v})$ was associated with a significant $(99 \%)$ reduction in bacterial density $(\geq 2$-log reduction, and $P<0.001)$ and comparable to mupirocin (2\%) treatment (Fig. 5b). These findings suggest that Lynronne-1 can effectively reduce the bacterial load in MRSA infected wounds.

The efficacy of Lynronne-1, Lynronne-2 and Lynronne-3 were subsequently tested in a murine model of MRSA deep thigh infection. ${ }^{25}$ The maximum tolerable dose of all three AMPs was predetermined to be $10 \mathrm{mg} / \mathrm{kg}$ in vivo in mice. Test animals were inoculated intramuscularly (IM) in the right thigh with $0.1 \mathrm{ml} /$ thigh of S. aureus MRSA ATCC 33591 (inoculum size of $1.57 \times 10^{5}$ CFU/ 

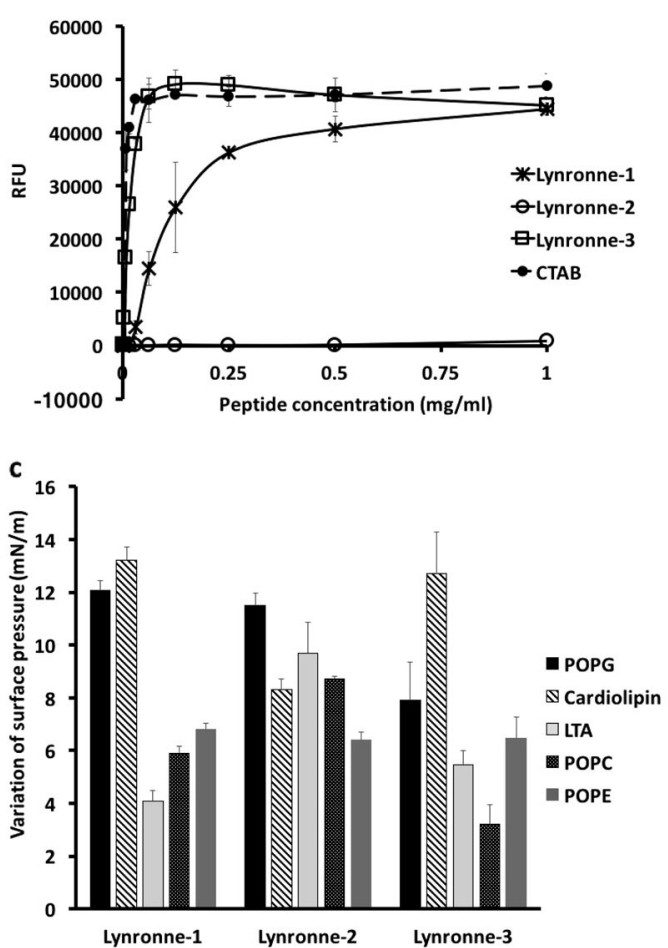

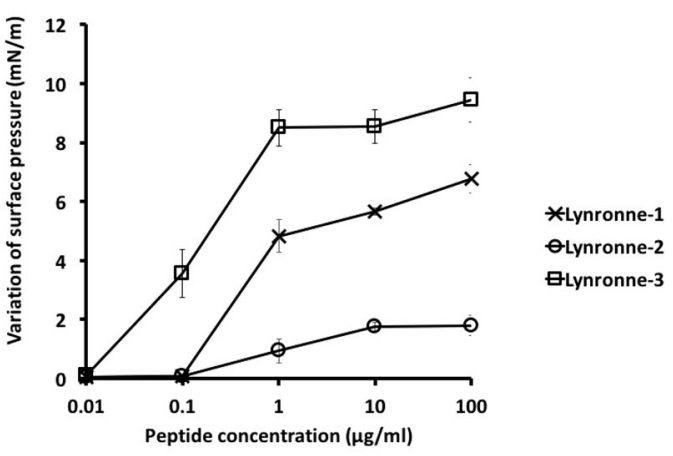

d

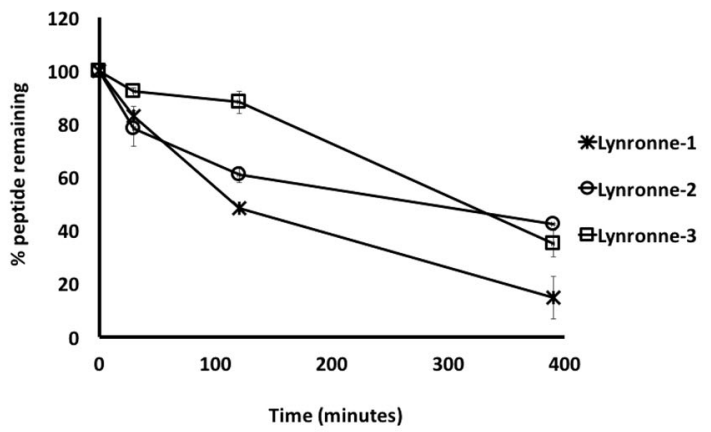

Fig. 3 Mode of action studies of Lynronne-1, Lynronne-2 and Lynronne-3 against MRSA: a Membrane permeabilization activity against MRSA USA300 measured by propidium iodide assay at $10 \mathrm{~min}$. b Dose-dependent interaction of peptides with total MRSA lipid extract, the initial surface pressure of lipid monolayer being $30 \pm 0.5 \mathrm{mN} / \mathrm{m}$. c Interaction of peptides (at $1 \mu \mathrm{g} / \mathrm{ml}$ final concentration) with pure lipids-maximal variation of surface pressure induced by the injection of peptide in lipid monolayer with initial surface pressure of $30 \pm 0.5 \mathrm{mN} / \mathrm{m}$. $\mathbf{d}$ peptide stability/degradation in $25 \%$ serum over time. Relative peptide concentrations were determined by integration of the peaks from RP-HPLC chromatograms (values from three independent replicates; error bars represent one standard deviation)

mouse) followed by treatment with Lynronne-1, Lynronne-2 and Lynronne-3 and the comparator antibiotic, vancomycin. Intravenous (IV) administrations of Lynronne-1, Lynronne-2 and Lynronne-3 at $10 \mathrm{mg} / \mathrm{kg}$ once or twice $(2 \mathrm{~h}$ or 2 and $8 \mathrm{~h}$ post infection) were not associated with any significant antimicrobial effects compared to the vehicle/control group $(0.9 \% \mathrm{NaCl})$. Vancomycin administered twice at $30 \mathrm{mg} / \mathrm{kg}$ IV) elicited a significant reduction $(\geq 99 \%$, 2-log reduction in $\mathrm{CFU} / \mathrm{g}$ and $P<0.001$ ). However, vancomycin at $10 \mathrm{mg} / \mathrm{kg}$ IV (administered twice) only elicited a significant reduction $(P<0.001)$ but not a 2 log reduction in colony counts compared to the control group (Fig. 5c).

Upon testing for stability of peptides, we observed that Lynronne- 1 rapidly degraded in the presence of serum with only 48 and $15 \%$ of the parent peptide remaining after $2 \mathrm{~h}$ and $6 \mathrm{~h}$ respectively. Lynronne- 2 and Lynronne- 3 were relatively more stable with $\geq 60$ and $42 \%$, as well as $\geq 88$ and $34 \%$ after $2 \mathrm{~h}$ and $6 \mathrm{~h}$ respectively (Fig. $3 d$ ). A similar pattern was observed when these peptides were treated with trypsin (Supplementary Fig. S6), a common feature among peptides that are susceptible to degradation by peptidases. ${ }^{26}$ This susceptibility to degradation may explain the poor efficacy of the peptides when administered intravenously.

\section{DISCUSSION}

AMPs are promising candidates for overcoming the critical and growing challenge of bacterial resistance to currently utilized antibiotics. The high cost and low success rate associated with the identification of novel and affective AMPs from natural sources has hindered the search for novel AMPs in the past. This hurdle has been overcome by new technological advances and improvements in traditional recombinant methods. ${ }^{23}$ Using a combination of functional metagenomics and computational approaches, we were able to show that the rumen microbiome is a promising resource for bio-prospecting novel AMPs, and these three peptides (Lynronne-1, Lynronne-2 and Lynronne-3), identified in this study are potential therapeutic candidates.

Lynronne-1, Lynronne- 2 and Lynronne-3 are efficacious against clinically important drug-resistant pathogens in in vitro models of infection. In addition, Lynronne- 1 decreased bacterial counts in MRSA wound infections using a murine model, similar to commercially used mupirocin ointment, suggesting that it could be used topically in the treatment of MDR bacterial infections. Lynronne 1, 2 and 3 displayed low haemolytic activity against blood cells and negligible cytotoxicity against mammalian cells. Results presented here suggest that loss of cell viability after exposure to Lynronne-1, Lynronne-2 and Lynronne-3 among many factors is due to membrane permeabilization, which contributes to membrane disruption and leakage of cell content. In addition to their broad antibacterial spectrum, selectivity and rapid killing of bacterial cells, Lynronne-1, Lynronne-2 and Lynronne-3 also showed a low tendency to select for resistance in the bacteria strains tested. The antimicrobial compounds discovered here are novel and demonstrate potent activity against clinically relevant human pathogens, rendering them as potential therapeutics. The identification of these novel AMPs support the hypothesis that the rumen is a promising resource for the discovery of novel antimicrobials with clinical relevance. 

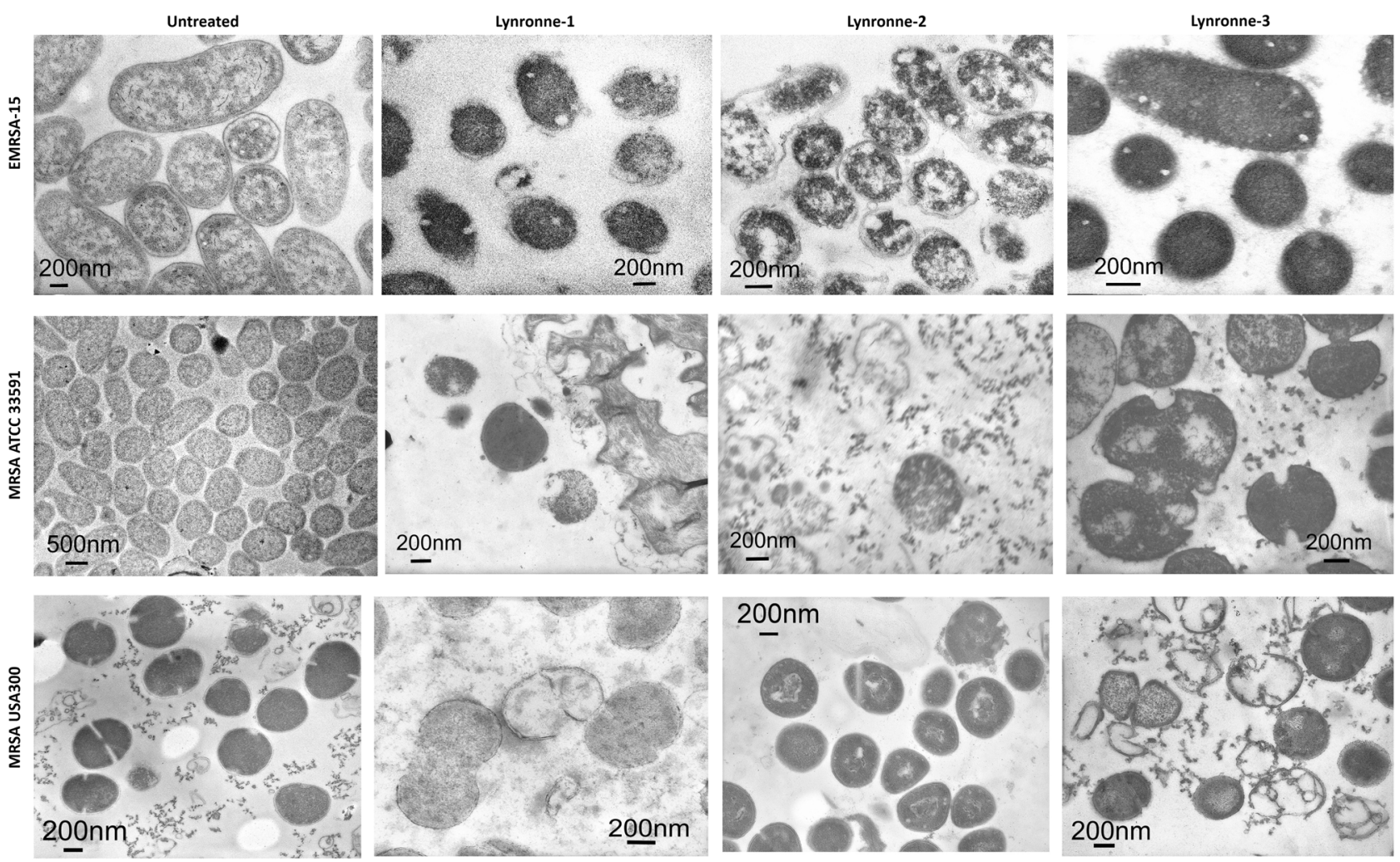

Fig. 4 Transmission electron micrographs of MRSA cells. Representative micrographs of untreated and peptide treated MRSA cells. Cells were treated at $3 \times$ MIC peptide concentration for $1 \mathrm{~h}$. Scale bars are 200 or $500 \mathrm{~nm}$ as shown on micrographs

\section{METHODS}

Functional antimicrobial activity screening of a rumen metagenomic library

A metagenomic library consisting of 8448 clones from a plant-associated rumen microbiome was prepared previously. ${ }^{15}$ The clones were transferred gently using multichannel pin replicators (Molecular Devices Ltd, Berkshire UK) onto Luria-Bertani agar plates containing a lawn $(500 \mu l)$ of S. aureus (MSSA) RN4220, E. coli K12, Salmonella enterica serovar Typhimurium SL1344, E. faecalis JH2-2 and L. monocytogenes NCTC 11994 serovar 4b $\left(\mathrm{OD}_{600}=1\right)$ using sterile pin replicators. Plates containing these pathogens were incubated at $37^{\circ} \mathrm{C}$ (or $30^{\circ} \mathrm{C}$ for L. monocytogenes) for $24 \mathrm{~h}$, and clearing zones around the fosmid clones were considered as indicative of clones containing gene inserts coding for antimicrobial compounds. Assays were performed in sextuplicates to ensure reproducibility.

Sequence-based screening of putative antimicrobial positive fosmid clones

Fosmids with putative antimicrobial activity were sequenced using the Genome Sequencer FLX platform (454 Life Sciences) according to manufacturer guidelines. Following sequence assembly using the default parameters on the gsAssembler software v.2.5.3 (Roche Life Sciences), sequences were trimmed and vector sequence were removed using BioEdit (version 7.1.11). ${ }^{27}$ VecScreen on NCBI was used to search the sequences for vector contamination. ORFs were determined using NCBI's ORF finder on the NCBI blast suite (v2.2.28). ${ }^{28}$

\section{In silico identification of AMPs}

Prediction of AMP sequences within the identified ORFs was achieved using a variety of software available at various public databases. Specifically, we used the antimicrobial peptide database, ${ }^{29}$ the Antimicrobial Sequence Scanning System (AMPA), ${ }^{30}$ BACTIBASE, ${ }^{31}$ collection of antimicrobial peptides (CAMP), ${ }^{18,32}$ and antibacterial peptides (AntiBP). ${ }^{33}$ Only ORFs that were predicted to encode putative AMPs within at least two of the utilized databases were explored further. The active sites within positive ORFs were predicted using $\mathrm{AMPA}^{30}$ and make up the peptides included in the peptide library to be screened for antimicrobial activity.
Peptide synthesis and antimicrobial screening

The peptides in the created peptide library were synthesized based on the SPOT technique and pure peptides ( $\geq 95 \%$ purity) were synthesized on resin using solid phase Fmoc peptide chemistry. ${ }^{16}$ The 135 peptides in the peptide library were screened for antimicrobial activity using both luminescent (Pseudomonas aeruginosa strain $\mathrm{H} 1001)^{34}$ and nonluminescent (epidemic methicillin resistant S. aureus EMRSA-15, Sal. typhimurium and E. coli $\mathrm{K} 12$ ) bacterial strains. Activity against nonluminescent bacteria strains was assessed by fluorescence readings (excitation/emission spectra of 560/590 nm) after the addition of resazurin dye $(100 \mu \mathrm{m}$ final concentration). The results from the screen were analysed using the MATLAB extension Gait-CAD as previously described. ${ }^{35}$ Concentration values with a $75 \%$ reduction of luminescence or fluorescence (IC75) in relation to untreated controls were computed. Three peptide activity classes: active (IC75 $\leq 0.25)$, semi-active $(0.25<\mathrm{IC7} 5 \leq 0.50)$ and inactive IC75 $>0.5$ were assigned against all microorganisms.

\section{Determination of MIC}

MICs were determined using a modified broth microdilution method ${ }^{36}$ in cation adjusted Mueller Hinton broth (MHB) following the International Organization for Standardization 20776-1 standard for MIC testing with a final bacterial inoculum concentration of $5 \times 10^{5} \mathrm{CFU} / \mathrm{ml}^{37}$ Peptides dissolved in sterile distilled water and comparator antibiotics dissolved in the appropriate solvents ${ }^{38}$ were added to sterile U-bottom polypropylene 96-well microplates at desired concentrations. MIC was defined as the lowest concentration of peptide or antibiotic, which inhibited the visible growth of bacteria after $18-24 \mathrm{~h}$ incubation at appropriate temperatures.

Time kill kinetics

Assessment of the bactericidal activity of peptides and comparator antibiotics was performed as previously described ${ }^{39}$ using exponentialphase cultures of pathogens grown in MHB $\left(1 \times 10^{8-10} \mathrm{CFU} / \mathrm{ml}\right)$. Peptides were added at concentrations 3 times their MIC values. Experiments were performed in quadruplicates, and CFU/ml was calculated at different time points after over overnight incubation. 

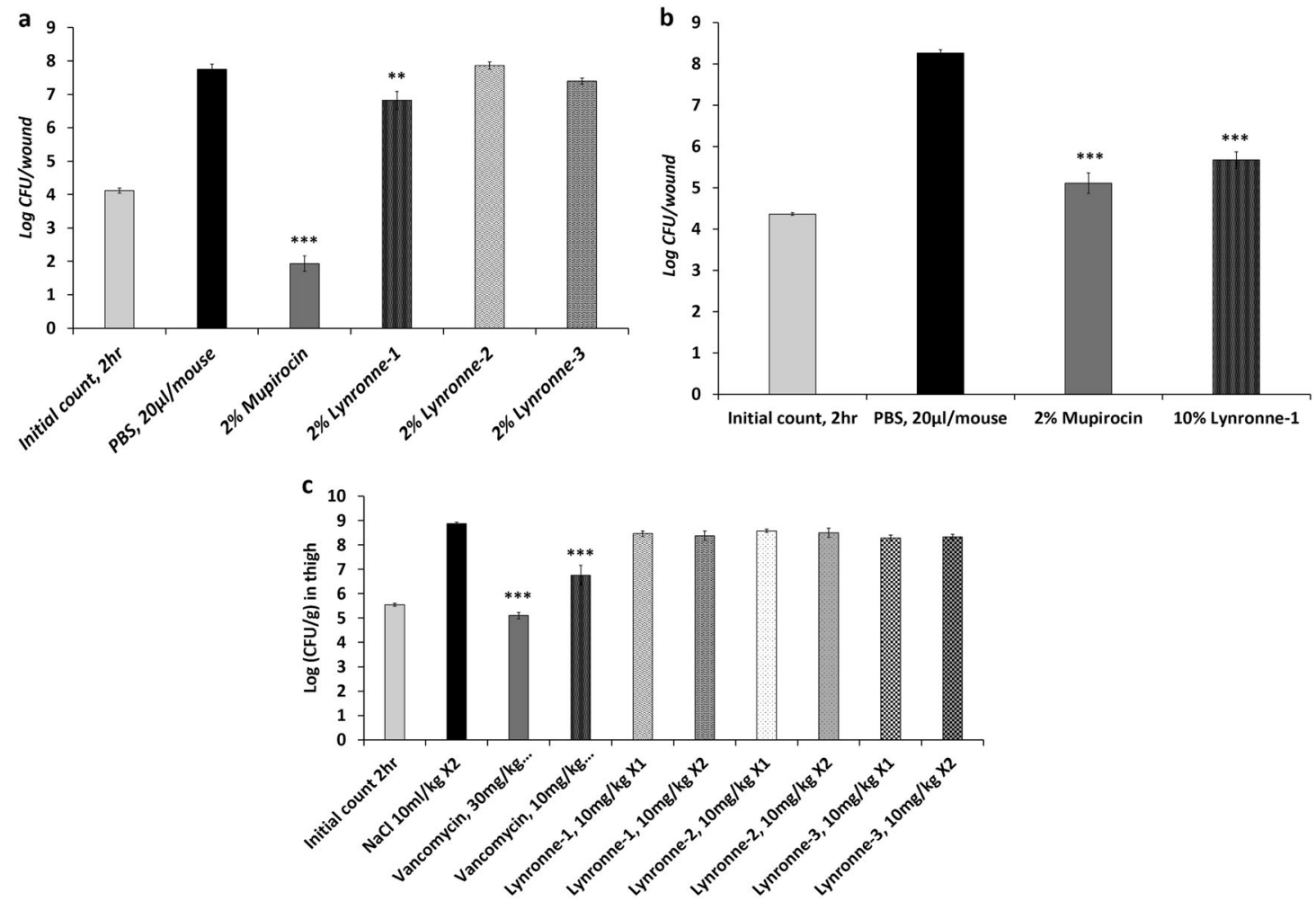

Fig. 5 In vivo efficacy in mouse models of infection. a Efficacy of Lynronne-1, Lynronne-2, Lynronne-3 and mupirocin against methicillin resistant S. aureus, USA300 MRSA (BAA-1717), wound infection in, ICR mice. Inoculum $=1.05 \times 10^{5}$ CFU/ml. b Efficacy of Lynronne-1 and mupirocin against methicillin resistant S. aureus, USA300 MRSA (BAA-1717). c Efficacy of intravenously administered Lynronne-1, Lynronne-2, Lynronne-3 and Vancomycin in the S. aureus (ATCC 33591) MRSA thigh infection model with neutropenic male ICR mice. Inoculum $=1.57 \times 10^{5}$ CFU/ml, $\times 1$ (administered once at $2 \mathrm{~h}$ ) or $\times 2$ (twice at 2 and $8 \mathrm{~h}$ post infection). ${ }^{*}, * * * * *$ Significant difference $(P<0.05,0.01$ and 0.001 , respectively) compared to the control group (PBS or $0.9 \% \mathrm{NaCl}$ ) was determined by one-way ANOVA followed by the use of a Dunnett's test

\section{Selection for AMP resistance}

To evaluate if populations of AMP-resistant bacteria could be selected, cultures were continuously exposed to Lynronne-1, Lynronne-2 and Lynronne-3 for a duration of 25 days, as previously described. ${ }^{40}$ Briefly, broth microdilution susceptibility testing was performed using a standard doubling-dilution series of Lynronne-1, Lynronne-2 and Lynronne-3 concentrations on day 1 . Following incubation of the cultures for $24 \mathrm{~h}$, and determination of the MIC, the well that contained the highest concentration of AMPs permitting growth was diluted 1:1000 in MHB and used to provide the inoculum for the next MIC assay; this process was repeated daily for 25 days.

\section{Erythrocyte leakage assay}

The haemolytic activity of peptides was determined by measuring haemoglobin leakage from human and sheep erythrocytes (Divbioscience, $\mathrm{NL}$ ) after $1 \mathrm{~h}$ incubation at $\mathrm{OD}_{450} \mathrm{~nm}$. Cetyltrimethylammonium bromide (CTAB), a non-specific detergent was also included as a positive control. Triton-X $100(0.1 \% \mathrm{v} / \mathrm{v})$ was also used as an indicator of $100 \%$ haemolysis while PBS treatment represented auto-haemolysis.

\section{Cytotoxicity of peptides}

Cytotoxic activity of the identified peptides was determined using HUVEC and HEPG2 cells as described previously. ${ }^{41,42}$ Three dose response parameters $50 \%$ growth inhibition $\left(\mathrm{Gl}_{50}\right)$, total growth inhibition (TGI) and $50 \%$ lethal concentration ( $\mathrm{LC}_{50}$ ) were calculated for each experimental agent and cellular tumor assay results are presented as the percent cell growth or percent tube length of specific activity. Significant responses were defined when observed cell growth was $\leq 50 \%$ and tube length was $\leq 70 \%$ using the proliferation and tube formation assays respectively. Permeabilization of eukaryotic membrane by Lynronne-1, Lynronne- 2 and Lynronne-3 was also investigated using HepG2 cells as described previously. ${ }^{43}$
Membrane permeabilization and peptide-lipid interactions

Membrane permeabilsation was evaluated using propidium iodide assay as previously explained, ${ }^{43}$ with CTAB as positive control. Peptide-lipid interaction was measured using reconstituted lipid monolayer. ${ }^{44}$ Total lipid extract from overnight liquid cultures of MRSA USA300 was obtained by Folch extraction, resuspended in chloroform and stored at $-20^{\circ} \mathrm{C}$ under nitrogen conditions. Pure bacterial and eukaryotic lipids, POPG, cardiolipin, LTA, POPE and POPC (Avanti Polar Lipid USA) were reconstituted in chloroform at $1 \mathrm{mg} / \mathrm{ml}$ and stored at $-20^{\circ} \mathrm{C}$ under nitrogen. Using a $50 \mu \mathrm{l}$ Hamilton's syringe, total MRSA lipid extract or pure lipids were spread at the surface of PBS creating a lipid monolayer at the air-water interface until an initial surface pressure of $30 \pm 0.5 \mathrm{mN} / \mathrm{m}$ was reached. This corresponds to a lipid packing density theoretically equivalent to that of the outer leaflet of the cell membrane. ${ }^{45}$ After $5-10 \mathrm{~min}$ of incubation allowing evaporation of the solvent and stabilization of the initial surface pressure, peptides were injected into the PBS ( $\mathrm{pH} 7.4$, volume $800 \mu \mathrm{l}$ ) sub-phase using a $10 \mu \mathrm{l}$ Hamilton syringe. The variation of the surface pressure caused by peptide injection was then continuously monitored using a fully automated microtensiometer ( $\mu$ TROUGH SX, Kibron Inc., Helsinki, Finland) until reaching equilibrium (maximal surface pressure increase usually obtained after 15-25 min). Critical pressure of insertion of each peptide in the different lipids was also determined by changing the initial pressure of lipid monolayer (from 10 and $30 \mathrm{mN} / \mathrm{m}$ ) and measuring the variation of pressure caused by the injection of peptide (at $1 \mu \mathrm{g} / \mathrm{ml}$ final concentration). All experiments were carried out in a controlled atmosphere at $20^{\circ} \mathrm{C}$ $\pm 1{ }^{\circ} \mathrm{C}$ and data were analyzed using the Filmware 2.5 program (Kibron Inc., Helsinki, Finland). Variation of surface pressure was plotted as a function of initial surface pressure and critical pressure of insertion was calculated as the theoretical value of initial pressure of lipid monolayer not permissive to peptide insertion, i.e., a variation of pressure equal to $0 \mathrm{mN} / \mathrm{m}$. The accuracy of the system under our experimental conditions was determined to be $\pm 0.25 \mathrm{mNm} / 1$ for surface pressure measurements. 


\section{Serum stability and trypsin degradation assays}

The stability of Lynronne-1, Lynronne-2 and Lynronne-3 in the presence of serum was investigated by monitoring the concentrations of the remaining soluble peptides by reverse phase high-performance liquid chromatography (RP-HPLC), as described previously by Nguyen and colleagues. ${ }^{26}$ Degradation of Lynronne-1, Lynronne-2 and Lynronne-3 in the presence of trypsin was adapted from a previously described method. ${ }^{46}$ Briefly, trypsin $(5 \mu \mathrm{l}$ of $0.5 \mathrm{ng} / \mathrm{ml})$ and $37.5 \mu \mathrm{l}$ trypsin activation buffer $(50 \mathrm{mM}$ Tris, $2 \mathrm{mM}$ $\mathrm{CaCl}_{2}, \mathrm{pH} 7.8-8$ ) was added to $7.5 \mu \mathrm{l}$ of $5 \mathrm{mg} / \mathrm{ml}$ Lynronne-1, Lynronne-2 and Lynronne- 3 and incubated at $37^{\circ} \mathrm{C}$ for different time points $(0,1,3$, and $24 \mathrm{~h}$ ). An aliquot from each reaction mixture at $0 \mathrm{~h}$ was prepared to allow matrix-assisted laser desorption/ionization time-of-flight (MALDITOF) mass spectrometric verification of the synthetic peptides prior to incubation. Trypsin action buffer $(5 \mu \mathrm{l})$ and peptides without trypsin was used as negative control. After the various incubation times, the reaction mixtures were acidified by addition of an equal volume $(50 \mu \mathrm{l})$ of $10 \%(\mathrm{v} / \mathrm{v})$ trifluroacetic acid (TFA) to stop further enzyme activity. Lynronne-1, Lynronne- 2 and Lynronne-3 degradation products were evaporated to dryness and reconstituted in acetonitrile/water/TFA (40/59.5/0.5\%, v/v/v). Samples $(1 \mu \mathrm{l})$ were carefully placed onto a stainless steel (MALDI) target, covered with $1 \mu \mathrm{l}$ of matrix (53 mM a-cyano-4-hydroxycinnamic acid in acetonitrile/water/TFA, 70/29.97/0.03\%, v/v/v) solution before analysis by mass spectrometry.

\section{Molecular modelling of AMP 3D structures}

The modelling of the 3D conformation of peptides was carried out using the de novo structural prediction method PEP-FOLD. ${ }^{17}$ The best 3D models for each peptide was selected according to PEP-FOLD score, based on the OPEP force field. ${ }^{47}$ Results were visualized using the PyMOL v1.7.6 program. ${ }^{48}$

\section{Transmission electron microscopy}

Effects of AMPs on bacterial cell morphology was investigated using transmission electron microscopy as described by Huws et al. ${ }^{49}$ Bacterial cultures in mid-log phase were treated with Lynronne-1, Lynronne-2 and Lynronne-3 (at $3 \times$ MIC for $1 \mathrm{~h}$ ) and then fixed with $2.5 \%(\mathrm{v} / \mathrm{v})$ glutaraldehyde. Cells were post-fixed with $1 \%$ osmium tetroxide $(\mathrm{w} / \mathrm{v})$, stained with $2 \%(\mathrm{w} / \mathrm{v})$ uranyl acetate and Reynold's lead citrate and observed using a JEOL JEM1010 transmission electron microscope (JEOL Ltd, Tokyo, Japan) at $80 \mathrm{kV}$.

\section{Quantification of anti-biofilm activity}

The effectiveness of Lynronne-1, Lynronne-2, and Lynronne-3 to prevent (a) biofilm attachment and (b) disrupt established biofilms was measured using a 96-well biofilm model..$^{50}$ Briefly, MRSA cultures grown in brain heart infusion (BHI) broth were washed, resuspended to an $\mathrm{OD}_{600 \mathrm{~nm}}=0.02$ in $\mathrm{BHI}$ broth and (a) treated with peptides (at $1 / 4 \times, 1 / 2 \times, 1 \times, 2 \times$ and $4 \times \mathrm{MIC}$ ) and incubated at $37^{\circ} \mathrm{C}$ for $24 \mathrm{~h}$ or (b) incubated at $37^{\circ} \mathrm{C}$ for $24 \mathrm{~h}$ to allow establishment of biofilms, washed in PBS to remove planktonic cells, and further incubated with peptides (at 1/4×, 1/2×, 1×, 2x and $4 \times$ MIC) in fresh $\mathrm{BHI}$ broth at $37^{\circ} \mathrm{C}$ for $24 \mathrm{~h}$. The biofilms were washed in PBS to remove planktonic cells, fixed with methanol, stained with $0.5 \%(\mathrm{w} / \mathrm{v})$ crystal violet and re-solubilized with $33 \%(\mathrm{v} / \mathrm{v})$ acetic acid. The optical density of biofilms was measured at $570 \mathrm{~nm}$.

In vivo efficacy of peptides in mouse models of MRSA skin and thigh infections

The efficacy of Lynronne-1, Lynronne-2 and Lynronne-3 for treating a wound infection caused by USA300 community-associated methicillin resistant S. aureus (MRSA, strain BAA-1717) was evaluated using a murine wound model with ICR mice. ${ }^{24}$ A sharp punch (ID $12 \mathrm{~mm}$ ) was used to create excisional skin wounds in groups of five female ICR mice (5-6 weeks old). The mice were inoculated topically on the wound area $(5 \mu \mathrm{l}$ per wound) with $1.05 \times 10^{5} \mathrm{CFU} /$ mouse of strain BAA-1717 suspended in $5 \mu \mathrm{l}$ PBS. Peptides (2 or $10 \% \mathrm{w} / \mathrm{v}$ ) in PBS (pH 7.4), control (PBS), and mupirocin $2 \%$ (Dermasafe ointment) were topically applied ( $20 \mu \mathrm{l} /$ mouse) directly to wounds $2 \mathrm{~h}$ post infection and once daily thereafter for three consecutive days. Test animals were sacrificed and the wound tissue was excised for enumeration of bacteria cells (CFU/wound). A two-log reduction in the bacterial count ( $\geq 99 \%$ reduction) relative to the control group indicates significant activity. Statistical significance $(P<0.05)$ was performed with one-way analysis of variance (ANOVA) followed by use of the Dunnett's method.

In the thigh infection model, using neutropenic mice, ${ }^{25}$ groups of five male ICR mice weighing $22 \pm 2 \mathrm{~g}$ were inoculated intramuscularly (IM) with S. aureus MRSA, ATCC 33591 (1.57 $\times 10^{5} \mathrm{CFU} /$ mouse $(0.1 \mathrm{ml} /$ thigh)) in the right thigh. Lynronne-1, Lynronne-2 and Lynronne-3 at $10 \mathrm{mg} / \mathrm{kg}$ were intravenously (IV) administered once $2 \mathrm{~h}$ post infection or twice 2 and $8 \mathrm{~h}$ post-infection. The reference substance, vancomycin, was also intravenously injected 2 and $8 \mathrm{~h}$ post-infection at 10 and $30 \mathrm{mg} / \mathrm{kg}$. Test animals were sacrificed $26 \mathrm{~h}$ after inoculation and the infected thighs were excised and the bacterial burden (CFU/gram) was determined.

\section{Data availability}

The datasets generated and/or analysed during the current study are available under the study name (SRP099633 Cow rumen Metagenome) in the GenBank database, (https://www.ncbi.nlm.nih.gov/).

\section{ACKNOWLEDGEMENTS}

This project was funded partly by the Cross River State Government of Nigeria, the Life Sciences Research Network Wales, RCUK Newton Institutional Link Fund (172629373), and the BBSRC UK (BB/L026716/1). P.N.G. acknowledges ERA NET IB2 (grant Nr ERA-IB-14-030) funded through the BBSRC grant BB/M029085/1. We are also grateful to Teri Davies for her technical assistance in setting up some experiments and to Dr Colin Greengrass, Prof Andrea Brancale and Prof Keith Harding for their advice. The in vivo mouse studies were carried out by Eurofins Panlabs.

\section{AUTHOR CONTRIBUTIONS}

L.O. and S.H. conceived the project. L.O., with help from H.V., T.W. and M.W., completed the laboratory work under supervision of S.H., J.E. and C.C. S.G. and L.O. completed the sequencing and downstream analysis of the sequences respectively. A.C. and N.F. assisted L.O. with transmission electron microscopy and 3D structural modelling respectively. F.P., O.G. and P.G. created the rumen fosmid metagenome library. L.O., M.M. and J.P. completed the membrane permeabilization and lipid binding assays. L.O., Y.L., F.L. and M.Z. completed the serum stability and degradation assays. K.H. and R.M. assisted L.O. with peptide library creation, screening and data analysis. M.H. and H.M. have provided valuable ideas into the project from the time of conception. L.O. wrote the paper with input from all co-authors.

\section{ADDITIONAL INFORMATION}

Supplementary information accompanies the paper on the npj Biofilms and Microbiomes website (https://doi.org/10.1038/s41522-017-0042-1).

Competing interests: The authors declare that they have no competing financial interests.

Publisher's note: Springer Nature remains neutral with regard to jurisdictional claims in published maps and institutional affiliations.

\section{REFERENCES}

1. WHO. The World Health Report-a Safer Future: Global Public Health Security in the 21st Century (World Health Organisation, Geneva 2007).

2. WHO. World Health Statistics (World health Organization, Geneva, 2014).

3. Prestinaci, F., Pezzotti, P. \& Pantosti, A. Antimicrobial resistance: a global multifaceted phenomenon. Pathog. Glob. Health 109, 309-318 (2015).

4. Czaplewski, L. et al. Alternatives to antibiotics-a pipeline portfolio review. Lancet Infect. Dis. 16, 239-251 (2016).

5. Hibbing, M. E., Fuqua, C., Parsek, M. R. \& Peterson, S. B. Bacterial competition: surviving and thriving in the microbial jungle. Nat. Rev. Micro 8, 15-25 (2010).

6. McCann, J. C., Wickersham, T. A. \& Loor, J. J. High-throughput methods redefine the rumen microbiome and its relationship with nutrition and metabolism. Bioinform. Biol. Insights 8, 109-125 (2014).

7. Morgavi, D. P., Kelly, W. J., Janssen, P. H. \& Attwood, G. T. Rumen microbial (meta) genomics and its application to ruminant production. Animal 7, 184-201 (2013).

8. Kalmokoff, M. L., Cyr, T. D., Hefford, M. A., Whitford, M. F. \& Teather, R. M. Butyrivibriocin AR10, a new cyclic bacteriocin produced by the ruminal anaerobe Butyrivibrio fibrisolvens AR10: characterization of the gene and peptide. Can. J. Microbiol. 49, 763-773 (2003). 
9. Meyerholz, D. K. \& Ackermann, M. R. Antimicrobial peptides and surfactant proteins in ruminant respiratory tract disease. Vet. Immunol. Immunopathol. 108, 91-96 (2005).

10. Russell, J. B. \& Mantovani, H. C. The bacteriocins of ruminal bacteria and their potential as an alternative to antibiotics. J. Mol. Microbiol. Biotechnol. 4, 347-355 (2002).

11. Ardvidson, S. Extracellular Enzymes. In Gram-positive Pathogens (ed Novick, R.) 478-485 (ASM Press, Washington, 2006).

12. Lee, C. Y. \& Lee., J. C. Staphylococcal capsules. In Gram-positive Pathogens (eds Fischetti, V. A. et al.) 456-463. (American Society for Microbiology (ASM), Washington DC., 2006).

13. Handelsman, J. Metagenomics: application of genomics to uncultured microorganisms. Microbiol. Mol. Biol. Rev. 68, 669-685 (2004).

14. Ferrer, M. et al. Novel hydrolase diversity retrieved from a metagenome library of bovine rumen microflora. Environ. Microbiol. 7, 1996-2010 (2005).

15. Prive, F. et al. Isolation and characterization of novel lipases/esterases from a bovine rumen metagenome. Appl. Microbiol. Biotechnol. 99, 5475-5485 (2015).

16. Hilpert, K., Winkler, D. F. H. \& Hancock, R. E. W. Peptide arrays on cellulose support: SPOT synthesis, a time and cost efficient method for synthesis of large numbers of peptides in a parallel and addressable fashion. Nat. Protoc. 2 1333-1349 (2007).

17. Maupetit, J., Derreumaux, P. \& Tuffery, P. PEP-FOLD: an online resource for de novo peptide structure prediction. Nucleic Acids Res. 37, W498-W503 (2009).

18. Waghu, F. H. et al. CAMP: collection of sequences and structures of antimicrobial peptides. Nucleic Acids Res. 42, D1154-D1158 (2014).

19. Gough, M., Hancock, R. E. \& Kelly, N. M. Antiendotoxin activity of cationic peptide antimicrobial agents. Infect. Immun. 64, 4922-4927 (1996).

20. Piers, K. L., Brown, M. H. \& Hancock, R. E. Improvement of outer membranepermeabilizing and lipopolysaccharide-binding activities of an antimicrobial cationic peptide by C-terminal modification. Antimicrob. Agents Chemother. 38, 2311-2316 (1994).

21. Alder, J. \& Eisenstein, B. The advantage of bactericidal drugs in the treatment of infection. Curr. Infect. Dis. Rep. 6, 251-253 (2004).

22. Drago, L. et al. Activity of levofloxacin and ciprofloxacin against urinary pathogens. J. Antimicrob. Chemother. 48, 37-45 (2001).

23. Ling, L. L. et al. A new antibiotic kills pathogens without detectable resistance. Nature 517, 455-459 (2015).

24. Gisby, J. \& Bryant, J. Efficacy of a new cream formulation of mupirocin: comparison with oral and topical agents in experimental skin infections. Antimicrob. Agents Chemother. 44, 255-260 (2000).

25. Andes, D. \& Craig, W. A. Pharmacodynamics of the new fluoroquinolone gatifloxacin in murine thigh and lung infection models. Antimicrob. Agents Chemother. 46, 1665-1670 (2002).

26. Nguyen, L. T. et al. Serum stabilities of short tryptophan- and arginine-rich antimicrobial peptide analogs. PLoS One. 5, https://doi.org/10.1371/journal. pone.0012684 (2010).

27. Hall, T. A. BioEdit: a user-friendly biological sequence alignment editor and analysis program for Windows 95/98/NT. Nucleic Acids Symp. Ser. 41, 95-98 (1999).

28. Wheeler, D. L. et al. Database resources of the National Center for Biotechnology. Nucleic Acids Res. 31, 28-33 (2003).

29. Wang, Z. \& Wang, G. APD: the antimicrobial peptide database. Nucleic Acids Res. 32, D590-D592 (2004).

30. Torrent, M. et al. AMPA: an automated web server for prediction of protein antimicrobial regions. Bioinformatics 28, 130-131 (2012).

31. Hammami, R., Zouhir, A., Ben Hamida, J. \& Fliss, I. BACTIBASE: a new webaccessible database for bacteriocin characterization. BMC Microbiol. 7, 89 (2007).

32. Waghu, F. H., Barai, R. S., Gurung, P. \& Idicula-Thomas, S. CAMPR3: a database on sequences, structures and signatures of antimicrobial peptides. Nucleic Acids Res. 44, D1094-D1097 (2016).

33. Lata, S., Sharma, B. K. \& Raghava, G. P. Analysis and prediction of antibacterial peptides. BMC Bioinformatics 8, 263 (2007)
34. Hilpert, K. \& Hancock, R. E. Use of luminescent bacteria for rapid screening and characterization of short cationic antimicrobial peptides synthesized on cellulose using peptide array technology. Nat. Protoc. 2, 1652-1660 (2007).

35. Mikut, R. Computer-based analysis, visualization, and interpretation of antimicrobial peptide activities. Methods Mol. Biol. 618, 287-299 (2010).

36. Wiegand, I., Hilpert, K. \& Hancock, R. E. Agar and broth dilution methods to determine the minimal inhibitory concentration (MIC) of antimicrobial substances. Nat. Protoc. 3, 163-175 (2008).

37. Jorgensen, J. H. Development of global standards for antimicrobial susceptibility testing: the ISO initiative. Clin. Microbiol. Newsl. 28, 153-157 (2006).

38. Andrews, J. M. Determination of minimum inhibitory concentrations. J. Antimicrob. Chemother. 48, 5-16 (2001)

39. Oliva, B. et al. Biological properties of novel antistaphylococcal quinoline-indole agents. Antimicrob. Agents Chemother. 47, 458-466 (2003).

40. Friedman, L., Alder, J. D. \& Silverman, J. A. Genetic changes that correlate with reduced susceptibility to daptomycin in staphylococcus aureus. Antimicrob. Agents Chemother. 50, 2137-2145 (2006).

41. Ahmed, S. A., Gogal, R. M. Jr. \& Walsh, J. E. A new rapid and simple nonradioactive assay to monitor and determine the proliferation of lymphocytes: an alternative to $[3 \mathrm{H}]$ thymidine incorporation assay. J. Immunol. Methods 170, 211-224 (1994).

42. Boyd, M. R. in Anticancer Drug Development Guide: Preclinical Screening, Clinical Trials, and Approval (ed Teicher, B. A.) pp. 23-42 (Humana Press, Totowa, New Jersey, 1997).

43. Di Pasquale, E. et al. Biophysical studies of the interaction of squalamine and other cationic amphiphilic molecules with bacterial and eukaryotic membranes: importance of the distribution coefficient in membrane selectivity. Chem. Phys. Lipids 163, 131-140 (2010).

44. Mahfoud, R. et al. pH-dependent interaction of fumonisin B1 with cholesterol: physicochemical and molecular modeling studies at the air-water interface. $J$. Agric. Food Chem. 50, 327-331 (2002).

45. Dennison, S. R., Kim, Y. S., Cha, H. J. \& Phoenix, D. A. Investigations into the ability of the peptide, HAL18, to interact with bacterial membranes. Eur. Biophys. J. 38 37 (2008).

46. McCrudden, M. T. C et al. The host defence peptide LL-37 is susceptible to proteolytic degradation by wound fluid isolated from foot ulcers of diabetic patients. Int. J. Pept. Res. Ther. 20, 457-464 (2014).

47. Maupetit, J., Tuffery, P. \& Derreumaux, P. A coarse-grained protein force field for folding and structure prediction. Proteins Struct. Funct. Bioinformatics. 69 394-408 (2007).

48. Schrödinger, L. L. C. (The PyMOL Molecular Graphics System, Version 1.7.6, 2010).

49. Huws, S. A. et al. Successional colonization of perennial ryegrass by rumen bacteria. Lett. Appl. Microbiol. 56, 186-196 (2013).

50. Hu, F. et al. Antimicrobial activity and safety evaluation of peptides isolated from the hemoglobin of chickens. BMC Microbiol. 16, 287 (2016).

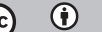

Open Access This article is licensed under a Creative Commons Attribution 4.0 International License, which permits use, sharing, adaptation, distribution and reproduction in any medium or format, as long as you give appropriate credit to the original author(s) and the source, provide a link to the Creative Commons license, and indicate if changes were made. The images or other third party material in this article are included in the article's Creative Commons license, unless indicated otherwise in a credit line to the material. If material is not included in the article's Creative Commons license and your intended use is not permitted by statutory regulation or exceeds the permitted use, you will need to obtain permission directly from the copyright holder. To view a copy of this license, visit http://creativecommons. org/licenses/by/4.0/.

(c) The Author(s) 2017 